\title{
Determinants of adoption of motorized water pump (evidence from Lake Abaya and chamo basins of gamo gofa zone, Southern Ethiopia)
}

\begin{abstract}
The main objective of this study is to identify and determine the adoption of motorized water pump. This study was conducted at Mirab Abaya and Arba Minch Zuria Woreda. The total sample size for this study is 196. From two selected Districts, five Villages were purposively selected. Data were collected though an interview schedule using structured questionnaire from respondent households. Mean, chi-squar, t-test and binary logistic model were employed for data analysis. The binary logit regression result revealed that, among the 13 independent variables included in the model, five variables were significantly determining the adoption of Motorized Water Pump. Household labor size was positively and significantly affects the adoption of motorized water pump at $\mathrm{p}<0.1$. Farm distance from water sources had significant negative effect on the adoption of motorized water pump at $\mathrm{p}<0.05$. Contact with development agents per month had significant positive effects on the adoption of motorized water pump at $p<0.05$. Market distance was found to influence adoption decision of the household head negatively and significantly at $p<0.5$. Contact with water users committee per month had significant positive effects on the adoption of motorized water pump at $\mathrm{p}<0.01$. Beyond household labor, looking for additional laborer is crucial to apply the improved irrigation technology. The farm land located far from the source of water has less chance to adopt the irrigation technology and vice versa. Access to market and market information is crucial for the farmers to improve production practices, to diversify their farm income, to sale their crops at an appropriate time, etc which enable them having better capital as well as better household asset.
\end{abstract}

Keywords: lake, water pump, chi-square, T-test, binary logit
Volume 5 Issue 4 - 2017

\section{Agidew Abebe, Amanuel Shewa}

Department of Rural Development and Agricultural Extension, College of Agricultural Science, Arba Minch University, Ethiopia

Correspondence: Agidew Abebe, Department of Rural Development and Agricultural Extension, College of Agricultural Science, Arba Minch University, Arba Minch, Ethiopia, Email agidew.abebe@gmail.com

Received: November 03, 2017 | Published: December 20, 2017

\section{Abbreviations: $L R$, likelihood ratio test; DF, degree of freedom}

\section{Introduction}

Ethiopia is fundamentally an agrarian country. Although the transformation towards a more manufacturing and industrially oriented economy is well underway, the agriculture sector continues to be the most dominant aspect of the Ethiopian economy, accounting for $46 \%$ of GDP, $73 \%$ of employment, and $80 \%$ of export earnings. Furthermore, the majority of the agriculture sector is made up of smallholder farmers who live in less than two hectares of land. As such, transformation of the agriculture sector will be central in Ethiopia's drive to reach middle-income country status by 2025.,

Irrigation plays a key role in the performance of agriculture, which increases income from agriculture sector. Income growth is essential for economic growth. There are four interrelated mechanisms by which irrigated agriculture can improve household income and food security, through:

i. Increasing farm production and productivity that helps very poor households meet the basic needs.

ii. Protecting against risks of crop loss due to erratic, unreliable or insufficient rainwater supplies

iii. Promoting greater use of yield enhancing farm inputs

iv. Creation of additional employment. ${ }^{3}$ Rogers et al., ${ }^{4}$ Adoption is defined as a decision to make full use of new ideas as the best course of action available.

The term adoption refers to the continued use by individuals or groups of a recommended idea or practice over a reasonably long period. On the other hand, some authors tried to show the similarity and difference between adoption and diffusion. ${ }^{5}$

\section{Statement of the problem}

In Ethiopia out of the total potential, about 10 to $12 \%$ of this potential is put under irrigated agriculture (both traditional and modern irrigation systems). The major limitations that constrained the development of the irrigation sub-sector are:

i. Predominantly based on traditional farming systems

ii. Inadequate improved agricultural inputs

iii. Limited access to improved irrigation technologies

iv. Inadequate trained human power

v. Inadequate extension services and capital

vi. Absence of appropriate institutions at different levels responsible for the promotion, planning and development of irrigated agriculture

vii. Inadequate information system on agricultural water management and irrigation development. ${ }^{6}$ 
Majority of Ethiopia's farmers have been using traditional way of agricultural practices. This has contributed for low productivity of the agricultural sector. To solve these problems, governmental and nongovernmental bodies have made restless efforts to bring about change in agricultural production system. They have introduced improved agricultural technologies like use of fertilizers, high yielding varieties of seeds, pesticides, improved farm implements, etc in relation to crops which seem better in yield. However, the introduced technologies are not widely accepted by farmers in different parts of the county as expected. This indicated that there are different factors directly or indirectly influencing the adoption of technologies that believed to bring change in smallholder farmers' productivity. ${ }^{7}$ The study area lacks in depth studies on identifying the determinants of the adoption of motorized water pump. Therefore, this study was initiated to identify determinates of the adoption of motorized water pump.

\section{Materials and methods}

The study was conducted in 2017. In this study, a multi-stage nonprobability and probability) sampling procedure was employed for the selection of District, sample Village and respondent households. In the first stage, the two Districts were selected purposively for the following reasons: The Districts located at the basins of Lake Abaya and Chamo; there is better use of motorized water pump and irrigation practice in the study areas that gives opportunity to local government in developing modern irrigation schemes; and accessible and availability of enough information about the practice.

In the second stage, five Villages (three from Mirab Abaya and Table I Sample villages and number of sample households for two strata two from Arba Minch Zuria Districts) purposively selected because of farmers have live in these Villages well used and adopted motorized water pump. In the third stage, the total households residing in the five Villages were stratified into two strata: adopter and non-adopter households. The population frame in the selected Village and the lists of adopter households in those Villages were obtained from Village Administration Offices. The total sample size determined through using published table. This table was designed exactly in the same way that the Internet calculators are. Based on this criteria, for this study the total sample size for the population size of 4492 with $\pm 7 \%$ precision levels, $95 \%$ confidence level and $\mathrm{P}=0.5$ (variability) is equal to196. ${ }^{8,9}$

In this study all adopters (83) from five sample Villages were included purposively due to their small size. However, the total sample sizes for non-adopter (113) from sample Kebekes were determined via probability proportionate to size procedure through the following formula:

$$
P_{i}=N_{i} / N
$$

Where: $\mathrm{P}_{\mathrm{i}}$ is proportion of population included in stratum $\mathrm{i}, \mathrm{N}_{\mathrm{i}}$ is the number of elements (total sample size), $\mathrm{N}$ is the total number of the population.

Therefore, the number of sample households from five sample Villages for two strata were shown below in the Table 1.

\begin{tabular}{lllllll}
\hline \multirow{2}{*}{ Sample woredas } & \multirow{2}{*}{ Sample kebeles } & \multicolumn{2}{l}{ Non-adopter households } & \multicolumn{2}{l}{ Adopter households } & \multirow{2}{*}{ Total sample household } \\
\cline { 3 - 6 } & & Total HH & Sample HH. & Total HH. & Sample HH. & \\
\hline \multirow{2}{*}{ Arba Minch Zuria } & Kanchama & 1325 & 34 & 20 & 20 & 54 \\
& Elgo & 1123 & 29 & 22 & 22 & 51 \\
\multirow{2}{*}{ Mirab Abaya } & Fura & 485 & 13 & 11 & 11 & 24 \\
& Alge & 517 & 14 & 9 & 9 & 23 \\
\multirow{2}{*}{ Total } & Yayke & 876 & 23 & 21 & 21 & 44 \\
& & 4326 & 113 & 83 & 83 & 196
\end{tabular}

Source: own field survey, 2017.

This determined sample size of non-adopter respondents were select from the population frame of non-adopter households of the respective Village through Systematic probability sampling (list sampling) technique. ${ }^{10}$ In this study, both primary and secondary data sources were employed. Primary data were obtained from respondents' farm household. Data were analyzed through mean, chi-square, t-test and binary logistic model was used to identify the determinants of adoption of motorized water pump. The data were computed through SPSS v16 software.

\section{Result and discussion}

\section{Descriptive and inferential statistics result of explanatory variables}

The chi-square result in Table 2 shows that sex and education level of respondents' had significant relationship with the adoption of motorized water pump at $1 \%$ significance level. Therefore, maleness of household head and increase in education level has its own influence on the adoption of motorized water pump.

The $\mathrm{t}$-value result also shows that the motorized water pump adopter households had significantly less mean age, farm distance from water source and development agents' office than non-adopter households. Therefore, increases in the mean of these variables have negative influence on the adoption of motorized water pump. On the other hand, the motorized water pump adopter households had significantly exceeded in the mean of household labor in adult equivalent; contact with development agents per month and contact with water users committees per month than non-adopter households. Therefore, increases in the mean of these variables have positive influence on the adoption of motorized water pump.

\section{Determinants of adoption of motorized water pump}

In the binary logit model result, the maximum likelihood estimates 
reveals that the adoption of motorized water pump was determined by the interaction of different factors: demographic, socio-economic, institutional and physical.

To test the measure of goodness of fit in logistic regression analysis, the Likelihood Ratio test (LR) and chi-square distribution with Degree of Freedom (DF) are equal to the number of independent variables included in the model. ${ }^{11}$ Consequently, the chi-square computed indicated, as the model was significant at $1 \%$ significance level.

The measure of goodness-off-fit in the logistic regression model is by observing the value in the prediction table as the model correctly predicted it or not. The fit is said to be good if the overall correct prediction rate exceeds $50 \% 12$. Accordingly, the prediction table shows that correctly predicted adopters were $97.6 \%$ whereas correctly predicted non-adopters were $99 \%$. However, the overall prediction was $98.4 \%$. The model results in Table 3 shows that, among the

Table2 Descriptive and inferential statistics result of explanatory variables 13independent variables included in the model, five variables significantly determined the adoption of Motorized Water Pump.

Household labor: Household size converted to adult equivalent is considered as the total active household members who reside in the respondent household. Large family size is assumed as an indicator of labour availability in the household. Large labour force in a household implies that the household may not need to hire more additional labor and then saved money due to use of own labor force will be used for purchasing farm inputs. This will increase household's probability of adoption of motorized water pump. The result of Logit model shows that household labor size was positively and significantly related to adoption of motorized water pump at $(\mathrm{p}<0.1)$. The odd ratio of 3.477 household labor sizes implies that other things being kept constant, the odds-ratio in favor of adopting motorized water pump increases by a factor of 3.477 as a farmer's household labor size increases by unit. This agreed with as labor accessibility increases, adoption increases and correlates positively. ${ }^{6}$

\begin{tabular}{|c|c|c|c|c|}
\hline \multirow{2}{*}{ Variables } & \multicolumn{2}{|l|}{ Mean } & \multirow[b]{2}{*}{$\chi_{2}$ and t-Value } & \multirow{2}{*}{ p-value } \\
\hline & Adopter $(\mathrm{N}=\mathbf{8 3})$ & Non-adopter $(\mathrm{N}=113)$ & & \\
\hline Sex of respondents & - & - & $8.47^{* * * *}$ & 0.005 \\
\hline Age of respondents & 42.8 & 45.9 & $-2.68^{* * * *}$ & 0.008 \\
\hline Household labor in AE & 4.36 & 3.16 & $5.47^{* * *}$ & 0 \\
\hline Education level of respondents & - & - & $21.98^{* * *}$ & 0 \\
\hline Land holding size & 1.4 & 1.39 & 0.454 & 0.65 \\
\hline Livestock holding in TLU & 3.86 & 3.78 & 0.342 & 0.733 \\
\hline Use of credit from institution last year & - & - & 0.272 & 0.781 \\
\hline Contact with DAs per month & 1.77 & 1.47 & $2.76^{* * * *}$ & 0.006 \\
\hline Farm distance from water source & 0.77 & 1.4 & $-8.79^{* * *}$ & 0 \\
\hline Attended on irrigation related training & - & - & 0.294 & 0.642 \\
\hline Contact with WUC per month & 1.73 & 0.008 & $24.47^{* * *}$ & 0 \\
\hline Distance from DA office & 0.42 & 0.596 & $-2.86^{* * *}$ & 0.005 \\
\hline Market distance & 0.799 & 0.791 & 0.106 & 0.915 \\
\hline
\end{tabular}

***, significance at I\% level.

Source: computed from own field survey, 2017.

Farm distance from water sources: Farm distance from water sources had significant negative effect on the adoption of motorized water pump at $5 \%$ significance level. The odds ratio disfavours the adoption of the pump by a factor of 0.003 for the respondents' farm distance from water source increased by $1 \mathrm{Km}$. Therefore, the farm land located far from the source of water has less chance to adopt the irrigation technology and vice versa. The reason behind this is, in the study area the major water sources for irrigation are lakes, ponds and rivers. When the farm far from these sources, it needs high financial costs to purchase the hose of motorized water pump and minimize the chances to adopt the pump. So it was not affordable by most farmers in the area.

Contact with development agents: The number of contact with Development Agents per month had significant positive effects on the adoption of motorized water pump at $5 \%$ significance level. The odds ratio 11.269 of number of contact with Development Agents per month showed that at $5 \%$ significance level, the odds ratio favoring the adoption of motorized water pump by a factor of 11.269 for the respondents' number of contact with the Development Agents per month increases in a unit. Therefore, respondents who highly contact with Development Agents per month have more chance to adopt the technology in the area. The result obtained from key informants interview revealed that, farmers' contact with and gained advice and training from Agricultural Development Agents initiated farmers' attending in training; improved their knowledge and skills on farming practices and improved farmers' utilization of improved irrigation technology (motorized water pump). This agreed with receiving training and advice from development agents and the perceived usefulness of development agents' advice are major factors that explain the likelihood of technology adoption and rate of input use. ${ }^{11}$

Market distance: Distance of household heads residence from all motorized water pump demand market was found to influence adoption decision of the household head negatively and significantly at $(p<0.5)$. The odd ratio of 0.042 distances from demand market 
implies that other things being kept constant, the odds-ratio disfavor of adopting motorized water pump by a factor of 0.042 as a distance from demand Market increases by one $\mathrm{km}$. Market distance inversely associated with market access and market information. Consequently, lack of access to market and market information is found to negatively influence income and hence well-being. Therefore, the low income and well-being have its own implication on adoption of farm technologies.

Contact with water users committees: The number of contact with water users committee per month had significant positive effects on the adoption of motorized water pump at $1 \%$ significance level. The odds ratio of 353.5 contacts with Contact with Water Users Committees s per month shows that other things being kept constant, at $1 \%$ significant level, the odds ratio favoring the participation in adoption of motorized water pump by a factor of 353.5 as a number of contacts with the Contact with Water Users Committees per month increases by unit. Therefore, respondents who highly contact with Contact with Water Users Committees per month have more chance to participate in adoption of motorized water pump in the area. The result obtained from key informant interview revealed that, farmers' contact with Contact with Water Users Committees improving farmers' chance to use irrigation water and improved irrigation technology (motorized water pump). The reason behind this was in the study area, the committees have high responsibility to control over common irrigation water sources.

Table3 Maximum likelihood estimates of the binary logit model and its odds ratio on the determinants of adoption of motorized water pump

\begin{tabular}{|c|c|c|c|c|c|c|}
\hline Variables & B & S.E. & Wald & df & P-Value & Odds ratio \\
\hline Sex of respondents(1) & 9.998 & 51.501 & 0.038 & 1 & 0.846 & 0 \\
\hline Age of respondents & -0.083 & 0.068 & 1.518 & 1 & 0.218 & 0.92 \\
\hline Education level & 0.678 & 1.034 & 0.43 & 1 & 0.512 & 1.969 \\
\hline Household labor in AE & $1.246^{*}$ & 0.656 & 3.604 & 1 & 0.058 & 3.477 \\
\hline Land holding size & 9.851 & 6.236 & 2.495 & 1 & 0.114 & $1.90 \mathrm{E} 4$ \\
\hline Farm distance from water source & $-5.902^{* *}$ & 2.729 & 4.677 & 1 & 0.031 & 0.003 \\
\hline Use of Credit (1) & 2.906 & 6.341 & 0.21 & 1 & 0.647 & 18.291 \\
\hline Training (1) & -1.662 & 1.307 & 1.618 & 1 & 0.203 & 0.19 \\
\hline Contact with DAs & $2.422^{* *}$ & 1.173 & 4.264 & 1 & 0.039 & 11.269 \\
\hline Market distance & $-3.169^{* *}$ & 1.452 & 4.764 & 1 & 0.029 & 0.042 \\
\hline Livestock holding in TLU & -0.744 & 0.691 & 1.159 & 1 & 0.282 & 0.475 \\
\hline Distance from DA office & -1.393 & 1.863 & 0.559 & 1 & 0.455 & 0.248 \\
\hline Contact with WUCs & $5.868^{* * *}$ & 1.853 & 10.028 & 1 & 0.002 & 353.515 \\
\hline Constant & -13.301 & 12.773 & 1.084 & 1 & 0.298 & 0 \\
\hline \multicolumn{7}{|l|}{-Correctly predicted adopter $=97.6$} \\
\hline \multicolumn{7}{|l|}{-Correctly predicted non-adopter $=99$} \\
\hline \multicolumn{7}{|l|}{-Overall percentage $=98.4$} \\
\hline \multicolumn{7}{|l|}{-Chi-square value $=20.141, p$-value $=0.000$} \\
\hline$-(-2 \log$ likelihood=25.048 $)$ & & & & & & \\
\hline
\end{tabular}

*,**and ***, significance at $10 \%, 5 \%$ and $1 \%$ level respectively.

Source: computed from own field survey, 2017.

\section{Conclusion and recommendation}

The study has explored the potential factors that affect the household annual gross farm income in the study area. Irrigated Land is a key asset of rural farm household and it had significant effect on the household annual gross farm income at $5 \%$ significance level. Access to irrigated land by allowing households to use family labor and other farm resources more intensively makes households more productive and hence better off. Therefore, it should be better to give attention by the concerned bodies on the different irrigation technologies to create access to them irrigation water.

The participation in adoption motorized water pump for irrigation enables farm households to improve their well-being by not only allowing higher income but also minimizing risk and smoothening household consumption. Therefore, the GOs and NGOs should focus attention in provision of credit to formers in extended repayment period; it may improve their initial capital to adopt the technology. 
Access to market and market information is crucial for the farmers to improve production practices, to diversify their farm income, to sell their crops at an appropriate time, etc which enable them having better capital as well as better household asset. Therefore, the concerned bodies should focus attention on provision of information about supply and demand market and creation of market accesses.

\section{Acknowledgements}

None.

\section{Conflict of interest}

The author declares no conflict of interest.

\section{References}

1. Abebaw S. Dimension and determinants of food insecurity among rural households in Dire Dawa area, Eastern Ethiopia. Thesis, School of Graduate Studies, Ethiopia: Alemaya University; 2003.

2. Agricultural Transforming Agency (ATA). Transforming agriculture in Ethiopia. Annual Report of 2013/2014. Addis Ababa, Ethiopia: Ethiopian Agricultural Transforming Agency; 2014. 8 p.

3. Haile T. Impact of irrigation development on poverty reduction in Northern Ethiopia. M Sc Thesis, Cork, Ireland: National University of Ireland; 2008.

4. Rogers EM, Shoemaker FF. Communication of Innovation: A Crosscultural Approach. 2nd ed. New York, USA: The Free Press; 1971. 476 p.

5. Dasgupta S. Diffusion of agricultural innovations in Village India. Department of sociology and anthropology, Canada: University of Prince Edward Island; 1989. 193 p.
6. Ministry of agriculture (MoA). Small-scale irrigation capacity building strategy for Ethiopia. Natural Resources Management Directorate through the support of GIZ. MoA, Natural resource sector, Sustainable Land Management Program, Addis Ababa, Ethiopia; 2011. p. 5-7.

7. Yishak G, Punjabi NK. Determinants of Adoption of Improved Maize Technology in Damot Gale Woreda, Wolaita, Ethiopia. M.Sc. Thesis. The department of agricultural extension, Ethiopia: school of graduate studies Alemaya University; 2005. 5 p.

8. Al-Subaihi AA. Sample size determination influencing factors and calculation strategies for survey research. Neurosciences. 2003;8(2):7986.

9. Glenn DI. Determining Sample Size, Document, Program Evaluation and Organizational Development. Institute of Food and Agricultural Sciences. Gainesville, FL 32611, USA: University of Florida; 2013. 3 p.

10. Kothari CR, Garg Gaurav. Research Methodology, Methods and Techniques. 4th ed. New Age International. Jaipur, India: University of Rajasthan; 2004. 418 p.

11. Gujarati DN. Basic Econometrics. 5th ed. New York, USA: the McGrawHill Book Co; 2004. 1003 p.

12. Ethiopia Development Research Institute (EDRI). Effects of Extension Services on Technology Adoption and Productivity among Female and Male Farmers. The case of four regions in Ethiopia: EDRI, Ethiopia Strategic Support Program II, Addis Ababa, Ethiopia; 2012. p. 1-2. 